\title{
Exploring the Health Case for Universal Basic Income: Evidence from GPs Working with Precarious Groups
}

\author{
${ }^{1}$ Faculty of Arts and Social Sciences, Department of Politics, Philosophy and Religion, Lancaster University, Lancaster, \\ United Kingdom of Great Britain and Northern Ireland, E-mail: m.johnson@lancaster.ac.uk, d.degerman@lancaster.ac.uk. \\ https://orcid.org/0000-0002-9987-7050.
}

\begin{abstract}
:
This article draws upon clinical experience of GPs working in a deprived area of the North East of England to examine the potential contribution of Universal Basic Income to health by mitigating 'patient-side barriers' among three cohorts experiencing distinct forms of 'precariousness': 1) long-term unemployed welfare recipients with low levels of education (lumpenprecariat); 2) workers on short-term/zero-hours contracts with low levels of education ('lower' precariat); 3) workers on short-term/zero-hours contracts with relatively high levels of education ('upper' precariat). We argue that any benefits must be accompanied by robust institutions capable of promoting health.
\end{abstract}

Keywords: Universal basic income, precariousness, general practice, inverse care law, welfare

DOI: $10.1515 /$ bis-2019-0008

People from disadvantaged socio-economic backgrounds face relative health deprivation. Evidence indicates that the lifestyles and living conditions of people in disadvantaged groups affect their health and that the institutional treatment of those groups inflicts specific challenges that can compound the deficit. This tendency has been conceptualised through the 'Inverse Care Law' (ICL), according to which the 'availability of good medical care tends to vary inversely with the need for it in the population served' (Tudor Hart, 1971, 7696). Since its conception over 40 years ago, the validity of the ICL has been affirmed by numerous studies (see McLean, Sutton, \& Guthrie, 2006). In the UK, studies of, and debates about, the basis of the ICL have centred on 'provider-side' factors and, in particular, the work of GPs, who occupy the frontline of the National Health Service (NHS) and thus hold a gatekeeping and referral, as well as treatment, role.

However, in contemporary Britain, a number of neoliberal socio-economic reforms, aimed at decreasing the size of the state, privatising national resources and services and reducing the scope of the welfare system, have created particular 'patient-side barriers' (see Jimmy \& Jimmy, 2011) for particular individuals. The nature and impact of these new barriers are diverse and require investigation. Standing (2011) has popularized the notion of precariousness to describe the unpredictable conditions faced by radically different people in contemporary market economies. Zero-hours contracts - such as those to which Sport Direct employees are subject are a salient example of precarious employment. But precarious employment can aslo include well-paid roles contingent upon piecework, such as those in - such as legal, IT and intellectual fields.

According to Standing's account, members of the 'precariat' lack occupational identities, treat work and other money-making activities instrumentally, are focused on the short-term and have no 'shadow of the future' hanging over their actions, leaving little incentive to sustain long-term relationships and productive, but unpaid, social activities. Standing (2015, p. 4) also refers dramatically to a 'lumpenprecariat', 'consisting of sad people lingering in the streets, dying miserably ... [T] hey are effectively expelled from society, lack agency and play no active role in the economic system beyond casting fear on those inside it'. While the account appears over-dramatized, there are people within the UK who are welfare-dependent, perhaps over several generations, and exist beyond paid employment. Such individuals do not necessarily pursue mainstream aspirations and their lives are not necessarily unpredictable. Indeed, some live relatively predictable lives grounded in their engagement with the welfare system (see Johnson, 2016).

Prima facie, there are good reasons to suspect that such relationships with work and welfare may impose different 'patient-side barriers' to health care. Anecdotal evidence from a recent participatory project, 'A CrossCultural Working Group on “Good Culture” and Precariousness' (see Johnson, 2016, 2017), indicated that those 
subject to zero-hours contracts worked when ill, sought means of 'patching themselves up', or avoided seeking GP services to deal with longer-term ailments in order to remain available for work (see Bennett, 2015). Conversely, recipients of working-age benefits sought means of upholding their benefits, viewing GPs as part of the welfare system by virtue of their provision of sick notes (see Burton, 2016). Such dynamics reflect contrasting relationships with GP services, but both may contribute to the ICL in different ways.

To address a range of issues fostered by the emergence of precariousness, Standing (2014) and others (e. g. Torry, 2013) have promoted the notion of Universal Basic Income (UBI). The idea of UBI - a monthly payment to all adult citizens (Wright, 2006, p. 5) - has recently broken into mainstream public discourse in the UK. Indeed, following trials in Finland and elsewhere (see also De Wispelaere, Halmetoja, \& Pulkka, 2018), the Labour Party is now committing to a trial of UBI (Cowburn, 2018) as part of a raft of measures designed to deal with the consequences of neoliberal reforms. This is due to the strong economic, political and ethical cases advanced for its introduction (e. g. Haagh, 2019; Pettit, 2007; Standing, 2011). However, as Labour recognised in requesting a summary of the health case for UBI (see Johnson \& Johnson, 2019), the public-health case for UBI is under-explored (Johnson \& Johnson, 2018; cf Forget, 2011; Haagh \& Rohregger, 2019). In that light, we wish to investigate the extent to which UBI may mitigate the ICL by ensuring that citizens in a range of 'precarious' circumstances have health-promoting relationships with the NHS.

This article uses qualitative survey- and focus-group data drawn from GPs working in areas of deprivation in the North East of England to explore: the particular health needs and dynamic of particular groups and how these contribute to the ICL; the role of GPs in dealing with such individuals; the potential for UBI to affect that role, and the epidemiological contribution of UBI to health. First, the article will briefly introduce the ICL, the concept of the 'precariat' and the relationship between UBI and health.

\section{The inverse care law}

Researchers have identified several interrelated factors that seem to contribute to the ICL, including patient multimorbidity, insufficient funding to GP practices in deprived areas, as well as GP attitudes and communication skills in dealing with deprived patients. Patients from socially deprived areas tend to show much higher rates of multimorbidity than more affluent patients. Recent research in Scotland shows that practices in the most deprived areas had $38 \%$ more patients with multimorbidity than those in the least deprived areas. Moreover, these patients frequently exhibited a combination of physical and mental conditions (McLean, Guthrie, Mercer, \& Watt, 2015). Deprivation levels also affect the age at which multimorbidity occurs. Among the most deprived, multimorbidity occurs 10 to 15 years earlier than among the most affluent (Barnett et al., 2012).

Funding is part but not all of the problem. Toynbee and Walker (2001) argued that health care inequality is due largely to insufficient funding, pointing out that disparities persist despite increases in health care expenditure in the 1990s. However, according to Watt (2002), while funding for the NHS has grown overall, the effect of this increase has simply been to level the playing field by ensuring that GPs in deprived areas receive the same pay as their colleagues in affluent areas. This has increased GP retention, but it has not addressed the root of the problem, which is the necessity for funding to address these additional needs. Even though deprived patients have a greater number and variety of health issues to address, the length of their visits to the GP tends to be shorter (Mercer \& Watt, 2007). One important reason for this is that the NHS Quality and Outcomes Framework - which determines the wages of GPs - incentivizes quantitative engagement with patients, rather than investing more time to address patients' issues more effectively (McLean et al., 2006; Watt, 2011).

When patients from deprived areas do engage with GPs, there is evidence to suggest that the quality of their treatment may be lower. According to Goddard, Gravelle, Hole, and Marini (2010), GPs tend to avoid locating to areas of socioeconomic deprivation and high pollution. Other research has shown that while the quality of routine services remains consistent across more and less deprived areas, the quality of more complex care is inversely related to deprivation (McLean et al., 2006). However, no studies have attributed this to poor performance during training and the more common explanation is lack of time and resources, which places significant strain on individual GPs (Fischer Pedersen \& Vedsted, 2014). It does not seem to be coincidental, therefore, that health professionals working with deprived patients often characterize their work as an 'endless struggle' (O'Brien, Wyke, Guthrie, Watt, \& Mercer, 2011).

Although lack of technical skill has not been implicated as a factor in the ICL, GPs' perceptions of deprived patients and soft skills in treating these individuals have been highlighted in recent studies. Research looking at GPs' attitudes toward people at the extreme lower end of the socioeconomic spectrum, such as the homeless and drug users, have found that negative perceptions can be a barrier to care (Lester \& Bradley, 2001; Neale, Tompkins, \& Sheard, 2008). Further away from the extreme end, views appear to be more nuanced (Russell \& Lough, 2010; Warwick Giles, Coleman, \& Checkland, 2016). One recent study in Glasgow found that GP train- 
ers from more affluent areas were more likely to name individual lifestyle choices as the main cause of health inequality, whereas trainers who worked in deprived areas cited more frequently structural factors (Blane, Hesselgreaves, McLean, Lough, \& Watt, 2013). It is, therefore, all the more striking that there are significantly fewer training opportunities in more deprived areas (Russell \& Lough, 2010).

GPs' attitudes towards patients appear to have a significant impact on doctor-patient communication in primary care. One large meta-study showed that communication between physicians and patients on the lower end of the socioeconomic scale tends to be poorer than with wealthier patients (Verlinde, De Laender, \& De Maesschalck, 2012). Another meta-analysis found that the communication style physicians adopt with poorer patients tends to be less positive, less informative and less likely to encourage dialogue about care (Willems, De Maesschalck, Deveugele, Derese, \& De Maeseneer, 2005). That being said, some poorer patients tend to prefer more paternalistic interactions with their GP (Mercer et al., 2016). According to a recent study, patients' perceptions of their GPs' empathy are an important predictor of positive overall health outcomes. However, the same study recorded that behaviour of GPs toward patients in deprived areas was less patient-centred than it was in affluent areas, which was also reflected in patients' perceptions of the encounter (Mercer et al., 2016).

This brief review indicates the multi-faceted and entrenched nature of the ICL and emphasises 'providerside barriers' to health care equality. As we will now explore, the literature on precariousness suggests that there are significant 'patient-side barriers' that need more fully to be understood.

\section{Precarious groups and basic income}

Standing's account of precariousness holds that socio-economic conditions are becoming ever increasingly insecure and unpredictable. However, his account of the 'precariat' is broad-brush and amorphous and the circumstances that may inflict most harm on individuals may not be the ones granted priority in his work. In particular, there is good reason to think that three different sets of circumstances may contribute differently to the ICL.

First, there seems good reason to have concern for a group identified as an extreme minority by Standing (2015): the lumpenprecariat. This consists of low-educated, long-term unemployed individuals in receipt of working-age benefits, potentially across generations. Such individuals do not necessarily pursue mainstream aspirations and live relatively predictable, but often traumatic, lives grounded in their engagement with the needs-based welfare system (see Johnson, 2016). Concomitant resource scarcity may impose what Mullainathan and Shafir (2014) describe as the 'psychological bandwidth tax', in which cognitive functioning is impaired by poverty, leading to short-term, counter-productive decision making. Such individuals may not have the educational resources to develop strategies to secure well-paid employment and have a perverse prima facie incentive to demonstrate long-term ill-health in order to sustain their welfare-based livelihood.

Second, there are individuals with low levels of education who are subject to low-paid, short-term contracted work. Prima facie, those employed on zero-hours contracts may struggle with lengthy and costly commutes, be unable to plan non-work activities for fear of being unable to fulfil work-obligations and risk termination, and are ineligible for working-age benefits. In these circumstances, they may be subject to the 'psychological bandwidth tax' and may be unable to make investments in health in terms of time to visit GPs and money to purchase prescriptions. With no 'shadow of the future', they may simply patch themselves up, meaning that more serious health conditions go unidentified and unaddressed.

Third, there is a group of highly educated short-term contract workers, such as those in the creative or legal professions, who are also deemed by Standing to be part of the precariat. While those individuals may be subject to short-term contracts, they exist within different social contexts and carry with them different social and cultural resources to navigate health and health systems. This is illustrated by Guy Opperman MP, who argued that he understood the circumstances of zero-hours employees, such as Bennett, by virtue of his having worked as a $£ 250$ per hour barrister for a firm without a contract guaranteeing numbers of hours (Chapman, 2017). Clearly, the pressures posed by such arrangements differ and there seems good reason to believe that highly educated, well-remunerated professionals in short-term forms of employment will bring different resources to their approach to health. In particular, they are less likely to be burdened as heavily by psychological bandwidth taxes and may be more able to develop tactics to engage with GPs, particularly with regard to overcoming interpersonal 'provider-side barriers'.

These potential 'patient-side barriers' of the first and groups in particular have been exacerbated by neoliberal reforms and have only become apparent and conceptualized in recent years. In this article, we examine the relevance to public health of the conditions of the following groups:

1. People who are long-term unemployed, with relatively low levels of education (lumpenprecariat) 
2. People who are working on short-term and zero-hours contracts, with relatively low levels of education ('lower' precariat)

3. People who are working on short-term and zero-hours contracts, with average or relatively high levels (degree level or above) of education ('upper' precariat) $)^{1}$

The importance of examining potential 'patient-side barriers' through GP clinical experience lies in their unique position as gatekeepers to needs-based welfare services.

Standing and others have long promoted UBI as a means of addressing several issues emerging from neoliberal reform. While data from UBI trials indicates a reduction in hospitalization and physician contact (Forget, 2011, p. 283) and a significant reduction in stress (Kangas, Jauhiainen, Simanainen, \& Ylikännö, 2019, p. 25), the ways in which the policy may promote health remain under-explored. Psychologists have called for the incorporation into studies of 'psychological impact measurements, including the healthy social indicators of sense of agency and control; uncertainty and security; connections with others; sense of meaning and purpose in life; and social trust and cohesion' (Psychologists for Social Change, 2017, p. 3). Given the possibility for 'patient-side barriers', there is prima facie reason to examine the ways in which the introduction of UBI may affect GP-patient relationships and, in turn, health outcomes. For example, the unconditional nature of the benefit grants freedom to individuals to resign from harmful positions (Pettit, 1993, p. 26; Widerquist, 2013, p. 27). This may reduce individuals' psychological bandwidth tax and increase the possibility of long-term health planning. Likewise, UBI may remove the perverse incentive towards maintenance of long-term illness and medication among the unemployed.

\section{Methods}

The concepts and issues examined are complex and cross disciplines. In order to understand the way in which GPs view patients from the three groups, we used a qualitative, phenomenological approach to engagement with GPs working in areas of deprivation as a scoping exercise. Our data collection proceeded in two stages. First, we deployed a questionnaire examining the nature and effects of socio-economic circumstances. Then, after a preliminary review, we proceeded to conduct a focus group - consisting of participants who had not responded to the questionnaire - examining 'patient-side barriers' in greater depth and UBI as a means of promoting health among specific groups.

\section{Participants}

The questionnaire was circulated to GP surgeries in deprived areas in the North East of England with a request to forward the call to any other interested surgeries in areas of deprivation. After an initial review, a call for expressions of interest in a focus group was circulated to a number of GPs who had expressed interest in the questionnaire, but had not returned completed forms. Seven GPs who had not completed the questionnaire were selected to participate. The focus group ran on the evening of July 11, 2017, a month after the 2017 UK General Election.

The self-selecting nature of the two groups necessarily presents issues of representativeness. There is no suggestion that the opinions of participants reflect uniformity in the profession. The participants have an explicit interest in promoting health among disadvantaged patients and seek actively to identify means of achieving that end (as noted by participant PF, lines $818-825$ of transcript).

\section{Procedure}

The questionnaire consisted of an explanatory priming section, containing links to videos and further reading, and 15 sections of primarily open-ended questions, with space for extensive answers.

The focus group was primed with a 15-minute presentation outlining the ICL, the socio-economic groups in question and UBI, which was delivered by the lead author. The subsequent 75-minute focus group was facilitated by a professional creative facilitator, without a researcher in the room. The use of a facilitator was recommended by GPs as a means of demonstrating independence from researcher bias. The facilitator employed an ORID approach to focused conversation. ${ }^{2}$ ORID seeks to move from objective questions focused on existing knowledge, to reflective questions on emotional responses to an issue, to interpretative questions that 
explore an issue to decisional questions that seek responses to the issue (Stanfield, 2000, pp. 16-21). In this instance, the discussion moved from knowledge of the concepts, to reflection by GPs on their engagement with patients, to interpretation of the nature of the needs of particular patient cohorts to examination of the potential contribution of UBI.

\section{Analysis}

The results section draws on data from both the returned questionnaires and the focus group, which were analysed systematically through close reading and re-reading. Citations to the data are coded $\mathrm{R}$ for respondent to the questionnaire, plus numeral 1-5 to denote respondent number, and $\mathrm{P}$ for participant in the focus group, plus figure A-G to denote participant identity. Line numbers are used as appropriate to reference individual questionnaires and the focus-group transcript. 'Participants' refers to all those who contributed to the study.

\section{Results}

\section{The inverse care law and 'patient-side barriers'}

Participants emphasized the diversity of belief and practice that exists throughout the profession, even among those operating within similar areas (PF, line 1004; PC, lines 1007-1008). They also recognized themselves as a particularly engaged element within the profession that wishes to promote health among the disadvantaged (see, for example, PF, lines 204-208; R2, lines 497-498; R3, lines 598-601). Still, all the participants identified the ICL as relevant and important to their practice and endorsed its validity in general (e. g. PB, lines 197-200). Clearly, GPs viewed the causes of the ICL as broad, heterogeneous and particular to specific groups and areas. Moreover, while they cited GP numbers, practice funding and funding in general as 'provider-side barriers', they also highlighted 'patient-side barriers': 'The inverse care law is relevant not just to the NHS, but to society more generally - factors such as levels of education, health literacy, sense of entitlement (to treatment, and to good health in general) and hope, all have a bearing on health' (R1, lines 16-19). Participants referred to colleagues whose approaches to treating disadvantaged groups were less sympathetic. However, the Participants themselves also expressed the kinds of fatalistic attitudes that contribute to the ICL: 'they will never stop smoking, so I won't try too hard' (R3, lines 644-646; see also PB, lines 503-508; PD, lines 791-792). In this respect, the participants approached the ICL epidemiologically by virtue of their acknowledgement of the broader set of cultural, social and psychological factors at play (see R3, lines 626-629).

Data from both the questionnaires and focus group supports the notion that patients' working conditions and relationship with the welfare system impose different 'patient-side barriers' on GP-patient relationships. The participants painted a bleak picture of patients who face pressures on their health security. This applies to all patients, but several participants stated that the three groups are distinct in their health needs and approaches to General Practice (PD, lines 97-98).

\section{Group 1: predictable ill-health}

Among the participants, Group 1, the lumpenprecariat, appeared to be of greatest concern (e. g. PF, lines 802 803; PC, lines 805-806). However, several contested Standing's articulation of the lumpenprecariat. As Respondent 1 (lines 60-67) noted, 'I see many patients who have never worked, and whose principal engagement with society is via the welfare state ... but a great many of my welfare-dependent patients are nowhere near that level of destitution'. Although participants referred to chaos and instability (PD, line 308; PA, line 927), there was also recognition that this is fairly consistent and predictable, with Participant E (lines 941-942; 517-520) stating that 'those with the shit life might not be that precarious'. Individuals in Group 1 were seen to face predictable patterns of health deterioration. Although the resilience of individuals within this Group was noted (PF, lines 173-179; PB, line 151), there was also suggestion of deficits in cultural, social and material means of resisting decline. Participants noted low expectation and aspiration as important features of patients' worldviews (PF, lines 85-89; PB, lines 148-149; R3, line 644), with individuals inhabiting intellectually, emotionally and even geographically constrained existences (PE, lines 532-538; PF, lines 540-547). Participant E (lines 517-520) stated that 'I feel like we're at the fourth generation now, where getting a job, going to school, getting your grades and making it out of there isn't what people aspire to any more'. Participant B (lines 522-523) added that 'the people with any aspiration left [areas of deprivation] very quickly'. Participant D (lines 526-530) agreed, arguing that 
even those that pursue education and employment often fail, leading peers to conclude that there is no point in trying.

Participants argued that such 'failure' contributed to poor health outcomes in two respects. First, Participant $C$ argued that low social status is, in and of itself, a determinant of health, stating that 'some research ... shows that actually educational attainment is more closely linked to health than income levels' (lines 614-617; see also R1, lines 142-143). These observations find solid support in the literature (see Marmot and Steptoe, 2008, 48; Tang, Rashid, Godley, \& Ghali, 2016, 1). Second,Participants noted that the lifestyles of people within Group 1 were associated with factors such as multimorbidity, particularly with regard to combinations of mood disorders and lifestyle diseases. Respondent 2 stated that

These patients tend to see their long-term chronic conditions as far less important than their more pressing and immediate health needs such as lack of income, risk of losing their homes, chaotic family situations and low mood. They are unlikely to prioritise quitting smoking, reducing their alcohol intake, improving their diet, and other risk factor management over issues which have a palpable impact on their current quality of life. (lines 427-432)

This may illustrate Standing's notion of individuals lacking a 'shadow of the future' over their actions, selecting short-term, sensory, hedonic, over longer-term, less instrumental, eudaimonic, well-being, interests (see PD, lines 901-904; cf Participant C, lines 210-214; see discussion of well-being in Crisp, 2017).

Participants suggested that this entrenched experience of poor educational outcomes, exclusion from employment and low status has been compounded by an increasingly punitive engagement with the welfare system that incentivizes long-term ill-health. Citing the 'benefits trap' phenomenon, participants asserted that patients in receipt of needs-based benefits view consultations as means of legitimizing welfare claims (R2, lines 451-453; R3, lines 696-698; R4, lines 1066). For example, Respondent 1 recalled a case in which a patient in receipt of disability benefit sought to continue treatment of pain through opiates, despite their ineffectiveness and side effects, since " Requiring morphine" was seen as a marker of severity (even though the morphine was ineffective)' (R1, lines 189-190). Similarly, Participant A (lines 133-134) stated that 'you want to prove to the state that you're as ill, and disabled, and incapable as you possibly can otherwise your kids might starve'. Respondent 1 argued that patients begin to identify themselves in " the sick role", which makes them more likely to pathologise symptoms that others may not' (R1, lines 97-98). Participant B summarized a common observation among participants in characterizing a life on needs-based benefits as 'almost like a full-time job' (PB, line 488), in which individuals are required to fulfil onerous job-seeking obligations for Jobseeker's Allowance. The 'chaotic' nature of such individuals' lives means that they are unable to meet those requirements, leading to their being sanctioned or having their benefits removed. As the notion of a 'psychological bandwidth-tax' suggests, the resulting resource scarcity contributes to mood disorders (see R3, line 643) and leads patients to seek Employment Support Allowance. For this, they require sick notes that can be dispensed most easily by GPs. This suggests that such patients increasingly view GPs as an integral part of the welfare system. Some participants stated that they see provision of sick notes as a social good or means of preventing a social harm. Participant B stated that they had gradually shifted away from encouraging work because of the negative consequences of inactivity and worklessness, and towards an almost unquestioning provision of support for claims in order that those who have genuine need are not deprived of essential resources (PB, lines 493-503).

The data supported the notion that GPs view Group 1 patients as passive, controlled (PE, lines 849-851; cf qualified response by R1, lines 153-155) and reactive, rather than active, in control and proactive, more used to having things done 'to them' (PE, line 845). This may contribute to the fatalism of some GPs noted above.

\section{Group 2: firefighting and perpetual anxiety}

Participants viewed Group 2 - the lower precariat - differently. Although some participants, such as R4 (lines 1013-1014) indicated that Group 2 experience 'increased smoking, obesity, diabetes type 2, depression, other mental health problems' in keeping with Group 1, others cited a number of different conditions and risk factors. Respondent 3 (lines, 650-651) supported this account, noting that Group 2 patients 'Often experience stress from bad working practices, not infrequently feel bullied by employers'. The constraints imposed by precarious employment contracts affect the ability of patients to attend GP and hospital consultations, as well as 'services such as physio/counselling' (R1, line 106). Indeed, individuals in such employment are also less likely to have access 'to Occupational Health so are without advocates or specialist advice in the workplace environment when they become sick' (R2, lines 378-379). The consequence, in Respondent 2's words, is that individuals within Group 2 
are more likely to work through periods of sickness, even if it would aid their recovery to have time off. This can mean that periods of illness are lengthened or have longer-term consequences. E.g. manual labourers who choose to work through episodes of mechanical back pain. (lines 370-374)

Whereas members of Group 1 are subject to a benefits trap, Participants indicated that members of Group 2 are subject to an employment trap that actively undermines their health. Zero-hours and short-term contracts offer few forms of protection. Neoliberal reforms to employment rights mean that employees sacked for alleged misconduct, often related to absence from work, become subject to a benefits sanction, preventing them from claiming Jobseekers Allowance for at least 13 weeks (Department for Work and Pensions, 2016). Individuals only have a right to appeal dismissals in a limited set of circumstances. When they do, this is a lengthy, costly and, ultimately, uncertain means of upholding interests (Hirsch, 2017). Being excluded from benefits is extremely problematic for Group 2, whose low-paid, precarious work means that they are constantly in and out of work (PD, 99-103). Not being able to access safety nets instills anxiety.

\section{Group 3: lifestyle choice and thwarted expectation}

Perhaps understandably, participants were likely to regard Group 3 - the upper precariat - as being of least concern. Participants had relatively little clinical experience of the group (e. g. R3, line 655; R1, line 124), suggesting that the group does not, yet, inhabit deprived areas in large numbers. This group does not face the same deficits in psychological, cultural, social and economic resources that are cited as factors in health problems in the first two groups. Participants who did have experience of working with the group attributed its members' precarious employment conditions to lifestyle choice driven by aspiration and the resources by which to pursue ambition (R3, lines 839-842; PA, lines 136-143). Whereas participants characterized Group 1's lifestyle as being dominated by predictable chaos and Group 2's by perpetual anxiety, participants were more likely to talk about Group 3 in terms of thwarted expectations, senses of entitlement and insufficient recognition (R2, lines 389-393). Those among the participants who had clinical experience referred to mood disorders triggered by threats to income through diminishing hours of work (R3, lines 655-657). The group's intellectual resources confer advantages in terms of dealing with 'patient-side barriers'. Participants asserted that although such patients 'share the concerns of the others about any conditions which might impact on their ability to do their job, due to the uncertain nature of it' (R2, lines 440-442), they are 'less "stuck" in this lifestyle' (R3, line 841), and 'educated enough to understand their stress is due to their working conditions' (R4, line 1044). They are also more 'help seeking' and 'more likely to accept and benefit from "talking therapies"' (R3, line 842). Significantly, Respondent 2 claimed that 'These patients with their higher educational level are more likely to engage with chronic disease management, to take a proactive approach to risk factor management, and to consult the GP for less serious health problems' (lines 462-464).

\section{Trends: upward and downward social mobility}

Despite the gradation in GP concern for the respective groups, the participants expressed concern at emerging social trends. In addition to a lack of upward social mobility, some participants noted downward social mobility from Group 2 - lower precariat - and even Group 3 - upper precariat - to Group 1 - lumpenprecariat. In addition to observing increased homelessness, participants highlighted instances of successful, highly educated individuals being drawn into destitution and long-term declining health (PE, lines 391-399). Participant $\mathrm{D}$ (lines 778-779) noted 'increasing numbers' of 'young, university-educated people who can't get a job'. Participant F (lines 785-786) mentioned a young person from a deprived background, who managed to complete university, but could not 'find a job so she's back in that family home with no money, no job, no prospects and becoming completely alienated and despairing'.

These general trends stoked serious concerns among the participants. Although participants expressed significant unease at the thought that they are, now, regarded as agents or instruments of the state (PA, lines 218-221), there was acceptance that GPs now play a time-consuming administrative role much more integrated into welfare services than before (see R2, lines 451-453; 512-515). Participants described their role as involving 'policing' (PE, lines 239-240), while others resisted or criticized the integration into the NHS of activities such as verification of identities traditionally associated with more formal roles within the state, such as those of border agents, bailiffs and prison officers (PC, lines 246-251; PE, lines 259-267). Given concern for the effects of the benefits trap on patient health, participants expressed a desire to 'divorce the health care from the money side' (PB, line 485). In part, this is because participants feel that GPs have a responsibility to foster well-being in its broadest sense by, for example, promoting self-worth by giving patients time and treating them with respect (PF, lines 857-858). 


\section{UBI: clarifying the doctor-patient relationship}

The discussion between the participants highlighted promises, dangers and limits of how UBI could shape the health of their patients and their relationship with GPs.

In terms of promises, participants considered UBI as a means to promote the self-worth of patients. Participant A (lines 141-142) stated that UBI 'would be a solution for all the pointless sick note system, the pointless reports to the benefits agency'. It would also remove 'shame' (PF, line 401), stigma ( $\mathrm{PB}$, lines 679-692) and the 'humiliating' process of form-filling to prove individual need (PD, lines 373-376). Participant E (lines 378-390; 577-578) observed that the existing needs-based process requires levels of resilience and administrative competence that may deprive those in need of vital resources, with obvious implications for their health (see examples given by PD, lines 549-571). Generally, participants believed that UBI would likely increase security in people's lives (PD, lines 437-438), forming a 'safety net for [the] chaos' (PA, line 927) of the modern world and a 'basic building block' (PA, line 599) around which to make choices. Participant C considered that it might offer recognition to 'people who are currently not rewarded - informal carers, housewives, people bringing up kids' (lines 603-604), which Participant E (line 609) claimed 'would make me change quite a bit of my consulting behaviour'. Participant F (lines 621-625; 655-657) suggested that the security of UBI would enable individuals currently under pressure to take precarious work, such as those in Groups 1 and 2, to develop long-term educational and career development plans to attain more secure work and pursue other, non-monetary social activities, which could lead to better health. As Participant D (lines 740-742) put it, 'they could then plan that career or job, or move house, or education or whatever, their learning. They can plan that and put time aside for it instead of thinking day-to-day or week-to-week'. Moreover, Participant D (lines 627-632) felt that UBI might reduce instability and insecurity within households as social units, increasing the possibility of individuals experiencing supportive environments conducive to broader health outcomes. Still, participants continued to emphasize the need for integration of different areas of the health service, including Health Visiting and General Practice (PG, line 837), as well as health with care and education (PD, lines 966-972; PF, lines 898-899), insofar as carers and teachers have a daily input into children's lifestyles (PA, lines 882-884; PC, line 886).

In terms of perils, they worried that worried that UBI might ultimately undermine the health of, for example, those currently in receipt of Personal Independence Payments who would be specifically vulnerable to a diminution in well-being if UBI were introduced without additional needs-based payments. As Participant $F$ (lines 956-959) noted, 'But to work out where that safety net is; would you have to alter it if there was just one of you or five of you? And how that would also impact on how you qualified for health care or social services or dementia tax or all those things?'. Indeed, Participant D (lines 446-468) added that unconditional payments could be means of government abrogating responsibility for, at present, universal health and education services and presenting health, for example, as a private good to be pursued privately. This point was supported by Participant E (lines 461-483), who cited examples from the US and UK of patients having to make choices about what medicines to take based on the cost of their prescriptions, undermining their health in the process. While these comments are interesting, we should note that issues of public administration are beyond the professional expertise and practical experience of the participants.

More important then are perhaps the perceived limits of UBI. As anticipated, given participants' concerns about the broader spectrum of 'patient-side barriers', such as education, and the effect of status, there was a sense that the impact of UBI would be dependent upon the socio-economic status of their patients. As Participant C (lines 617-619) put it, 'this only tackles the income thing, it doesn't really get at the problem we've got of inequality in the country and this idea of really low status amongst some people' (see also PD, lines 438-439; PF, lines 662-663). Although UBI could help make doctor-patient relationships more directly health-focused, some participants said that it would leave some areas of concern unaddressed, such as the need to help individuals make choices that promote longer-term interests, rather than 'making decisions that are making them more and more unhealthy' (PF, lines 898-899).

\section{Discussion}

The results indicate that this cohort of GPs working in areas of deprivation believe that: i) the ICL is valid; ii) its causes are many and varied; iii) the socio-economic conditions within which individuals exist are conducive to the creation of 'provider-side' and 'patient-side barriers'; iv) the three groups outlined above face different types of barriers; v) UBI offers qualified potential to address some of these barriers, but that it needs to be complemented by effective, reliable institutions, particularly in healthcare. While the literature supports findings i-iii and vi, findings iv and $v$ challenge the treatment of precariousness and UBI within the literature.

Standing's work raises concern about the way in which highly educated, creative workers face increasing precariousness in work (e. g. Armano \& Murgia, 2014). However, the data from this study suggests that these 
workers do not easily fit into the same category as low-paid, low-educated workers, who are more likely to experience, but less able to deal with, Mullainathan and Shafir's (2014) 'psychological bandwidth tax'. Moreover, while welfare recipients may not be 'lying around on the streets, dying miserably', they are trapped and ought to be of greatest concern for a publicly-funded health system.

Epidemiological and evolutionary-psychological and literature has highlighted the adverse health-effects of resource scarcity and unpredictability - two constituent features of insecurity and central drivers of the ICL. Frankenhuis, Panchanathan, and Nettle (2016) demonstrate that such conditions foster short-term thinking that can harm long-term health and well-being. Indeed, exposure to such conditions in childhood causes cellular damage, inflicting permanent disadvantage on individuals in adulthood (Nettle et al., 2017). Indicating the dangers of downward social mobility, Frankenhuis, Panchanathan and Nettle argue that 'people from supportive environments, when exposed to harsh-unpredictable environmental cues, shift toward a presentorientation' (2016, p. 76). Although high childhood socio-economic position can provide defence against the effects on health of low adult socio-economic position, the defence is not impenetrable (Nettle \& Bateson, 2017).

These factors may be particularly relevant to Group 3, the upper precariat. Participants' reference to Group 3 members retaining long-term health planning capacities even during periods of scarcity may be explained in part because patients regard experience of scarcity as a transitory phase in an ambitious life-plan. However, the noted overall trend towards a lowering of wages and a reduction in security, even among previously well-remunerated professions, is concerning insofar as hunger is associated with impulsivity and risk taking (Nettle, 2017). However, we ought particularly to be concerned about the effects of unpredictability and scarcity on Groups 1 and 2 - the lumpen- and lower precariat. From an evolutionary perspective, we are predisposed to invest less in long-term health if an early death is anticipated. Indeed, as Standing's concern for the 'shadow of the future' suggests, such conditions promote impulsive, short-term action (Páal, Carpenter, \& Nettle, 2015). This was borne out by a recent empirical study of health behaviours among older adults in England, which showed that '[1]ower anticipated survival was associated with decreased probability of adopting healthier patterns of physical activity, and increased probability of becoming a smoker at follow up' (Adams, Stamp, Nettle, Milne, \& Jagger, 2015, p. 1). It is further explained by the notion that 'preference for immediate payoff or subjective lack of control are responses delivered by an evolved psychology attuned to cues of extrinsic mortality, delivering adaptively patterned shifts in behaviour, which then become propagated through social transmission' (Pepper \& Nettle, 2014, pp. 236-237). Counter-intuitively, Pepper and Nettle (2014, p. 238) argue that public health efforts to raise awareness of the dangers of health-impeding behaviours may actually increase health inequality, as individuals in, for example, Groups 1 and 2 are likely to view those messages as cues to extrinsic mortality and bury themselves further in self-destructive, hedonistic short-term thinking.

UBI does not deal directly with these processes. However, in thinking epidemiologically about health, the participants indicate that it may create a context in which motivated individuals feel more able to advance longterm personal and professional development strategies. The evolutionary psychological literature indicates that this may be because it reduces extrinsic mortality cues. Perhaps unsurprisingly, given their positions, participants in this study were clear that any such policy must be accompanied by robust, sustained, and well-funded health and education services in order that individuals can make use of their new-found circumstances. This is an important qualification to justifications for UBI that focus primarily on unconditionality of payment, but neglect the institutional context in which these take place. Indeed, the data as a whole indicates the continuing importance of the NHS as an institution to people's well-being in general and presents a dystopian picture of life in its absence.

\section{Conclusion}

The findings presented here reflect the clinical reflections of GPs on their engagement with particular groups of patients. They indicate that, on the one hand, the Inverse Care Law still applies to the UK. However, on the other, precariat groups have distinct health needs and barriers (particularly 'patient-side barriers') to health which no single policy can resolve. Therefore, the potential benefits of UBI need to be understood within this context and evaluated with regard to the broader set of institutions available to individuals (see Martinelli, 2017). At the same time, as the participants note, UBI must be seen within the context of larger political and economic changes within the UK health sector. For example, they raised concerns that an underfunded UBI could be used as a political cloak to increasingly marketize and privatize health and social services and weaken the underlying public institutional structures. In this case, a poorly structured and underfunded UBI could potentially intensify precariat health challenges. Finally, it is important to note that the distinctiveness of the NHS and the underlying complexity of its interaction with multiple social groups and structures (Geyer \& Rihani, 2010) means that we must be very careful when we extrapolate the 'lessons learned' from ongoing studies in other countries. With trials of UBI planned by Labour and others, our research suggests that the 
policy can make a contribution to public health, particularly among the worst off, but that this will depend on a wide range of other social, economic and institutional factors and will likely have a variable effect within the sub-groups of the precariat itself.

\section{Notes}

1 We owe the lower/upper precariat distinction to the helpful suggestion of one of our reviewers.

2 The letters in ORID stand for 'Objective', 'Reflective', 'Interpretive', and 'Decisional', each word denoting a theme that should guide the behavior and questions of the facilitator.

\section{References}

Adams, J., Stamp, E., Nettle, D., Milne, E. M. G., \& Jagger, C. (2015). Anticipated survival and health behaviours in older english adults. PloS One, 10(3), e0118782.

Armano, E., \& Murgia, A. (2014). The precariousnesses of young knowledge workers. Clobal Discourse, 3(3-4), 486-501.

Barnett, K., Mercer, S. W., Norbury, M., Watt, G., Wyke, S., \& Guthrie, B. (2012). Epidemiology of multimorbidity and implications for health care, research, and medical education. The Lancet, 380(9836), 37-43.

Bennett, T. (2015). Work and Unemployment. YouTube. 21 December. Retrieved from 6 August 2017 https://youtu.be//PLCZoQgMok

Blane, D. N., Hesselgreaves, H., McLean, G., Lough, M., \& Watt, G. (2013). Attitudes towards health inequalities amongst GP trainers in Clasgow, and their ideas for changes in training. Education for Primary Care, 24(2), 97-104.

Burton, C. (2016). Biographical Interview. YouTube. 22 February. Retrieved from 6 August 2017 https://youtu.be/CYN]A-rrqvU

Chapman, B. (2017). Tory minister says he understands life on zero-hours contracts because he used to be $f 250-a n$-hour barrister. The Independent, 16 ]une. Retrieved from 6 August 2017 http://www.independent.co.uk/news/business/news/tory-dwp-minister-zero-hourscontract-guy-opperman-barrister-250-hour-gig-economy-work-pensions-a7793241.html

Cowburn, A. (2018). Labour set to include pilot of radical basic income policy in next manifesto, John McDonnell says. The Independent. 31 July. Retrieved from 27 August 2018 https://www.independent.co.uk/news/uk/politics/labour-universal-basic-income-john-mcdonnell-partymanifesto-corbyn-poverty-social-benefits-a8471616.html

Crisp, R. (2017). Well-Being. In N. Zalta (Ed.), The Stanford Encyclopedia of Philosophy. Retrieved from 27 September 2017 https://plato.stanford.edu/archives/fall2017/entries/well-being

De Wispelaere, J., Halmetoja, A., \& Pulkka, -V.-V. (2018). The rise (and fall) of the basic income experiment in Finland. CESifo Forum, 19(3), 15-19.

Department for Work and Pensions. (2016). Guidance: Jobseeker's Allowance sanctions: how to keep your benefit payment. Department for Work and Pensions Website. 9 December. Retrieved from 31 July 2017 https://www.gov.uk/government/publications/jobseekers-allowancesanctions-leaflet/jobseekers-allowance-sanctions-how-to-keep-your-benefit-payment

Fischer Pedersen, A., \& Vedsted, P. (2014). Understanding the inverse care law. International Journal for Equity in Health, 13(1), 405-408.

Forget, E. L. (2011). The town with no poverty: The health effects of a Canadian guaranteed annual income field experiment. Canadian Public Policy, 37(3), 283-305.

Frankenhuis, W. E., Panchanathan, K., \& Nettle, D. (2016). Cognition in harsh and unpredictable environments. Current Opinion in Psychology, 7, 76-80.

Ceyer, R., \& Rihani, S. (2010). Complexity and public policy. London: Routledge.

Coddard, M., Gravelle, H., Hole, A., \& Marini, C. (2010). Where did all the GPs go? Journal of Health Services Research \& Policy, 15(1), 28-35.

Cordon, N. (2014). The conservative case for a guaranteed basic income. The Atlantic. 6 August. Retrieved from 31 July 2017 https:/www.theatlantic.com/politics/archive/2014/08/why-arent-reformicons-pushing-a-guaranteed-basic-income/375600/

Haagh, L. (2019). The Case for Universal Basic Income. Cambridge: Polity.

Haagh, L., \& Rohregger, B. (2019). Universal basic income policies and their potential for addressing health inequities: Transformative approaches to a healthy, prosperous life for all. Copenhagen: WHO.

Hirsch, A. (2017). On tribunal fees, the government has been given a lesson in patriotism. The Guardian [Online]. 27 July. Retrieved from 31 July

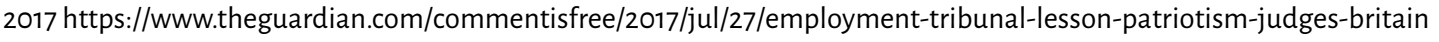

Jimmy, B., \& Jimmy, J. (2011). Patient medication adherence. Oman Medical Journal, 26(3), 155-159.

Johnson, M. T. (2016). 'Big society', 'good culture' and aspiration. British Academy Review, 27, 34-38.

Johnson, M. T. (2017). A Cross-Cultural Working Croup on “Cood Culture” and Precariousness [Online]. Retrieved from 31 July 2017 http://wp.lancs.ac.uk/good-culture/

Johnson, M. T., \& Johnson, E. A. (2018). Stress, Domination and Basic Income: Considering a citizens' entitlement response to a public health crisis. Social Theory \& Health. doi:10.1057/s41285-018-0076-3

Johnson, M. T. and Johnson, E. A. (2019). The Health Case for Universal Basic Income: Supporting Document for Basic Income as Common Dividends: Piloting a Transformative Policy: A Report for the Shadow Chancellor of the Exchequer (Online), Lancaster: Lancaster University, <https://www.academia.edu/38138513/The_Health_Case_for_Universal_Basic_Income>, [Accessed 25 October 2019].

Kangas, O., Jauhiainen, S., Simanainen, M., \& Ylikännö, M. (2019). The basic income experiment 2017-2018 in Finland. Preliminary results. Helsinki: Ministry of Social Affairs and Health.

Lester, H., \& Bradley, C. P. (2001). Barriers to primary healthcare for the homeless. European Journal of Ceneral Practice, 7(1), 6-12. 
Marmot, M. G., \& Steptoe, A. (2008). Whitehall II and ELSA. In National Research Council (Eds.), Biosocial Surveys. (pp. 42-59). Washington: National Academies Press.

Martinelli, L. (2017). Assessing the case for a universal basic income in the UK. Bath: Institute for Policy Research.

McLean, G., Guthrie, B., Mercer, S. W., \& Watt, G. C. (2015). General practice funding underpins the persistence of the inverse care law. British Journal of Ceneral Practice, 65(641), e799-e805.

McLean, G., Sutton, M., \& Guthrie, B. (2006). Deprivation and quality of primary care services. Journal of Epidemiology and Community Health, 60(11), 917-922.

Mercer, S. W., Higgins, M., Bikker, A. M., Fitzpatrick, B., McConnachie, A., Lloyd, S. M., ... Watt, G. C. M. (2016). Ceneral practitioners empathy and health outcomes. The Annals of Family Medicine, 14(2), 117-124.

Mercer, S. W., \& Watt, G. (2007). The inverse care law. The Annals of Family Medicine, 5(6), 503-510.

Mullainathan, S., \& Shafir, E. (2014). Scarcity [Kindle]. London: Penguin.

Neale, J. N., Tompkins, C., \& Sheard, L. (2008). Barriers to accessing generic health and social care services. Health and Social Care in the Community, 16(2), 147-154.

Nettle, D. (2017). Does hunger contribute to socioeconomic gradients in behaviour? Frontiers in Psychology, 8, 358. doi:10.3389/fpsyg.2017.00358

Nettle, D., Andrews, C., Reichert, S., Bedford, T., Kolenda, C., Parker, C., ... Bateson, M. (2017). Early-life adversity accelerates cellular ageing and affects adult inflammation. Scientific Reports, 7, 40794. doi:10.1038/srep40794

Nettle, D., \& Bateson, M. (2017). Childhood and adult socioeconomic position interact to predict health in mid life in a cohort of British women. Peer]ournal, 5, e3528. DOI doi:10.7717/peerj.3528.

O’Brien, R., Wyke, S., Guthrie, B., Watt, G., \& Mercer, S. (2011). An 'endless struggle': a qualitative study of general practitioners' and practice nurses' experiences of managing multimorbidity in socio-economically deprived areas of Scotland. Chronic Illness, 7(1), 45-59.

Páal, T., Carpenter, T., \& Nettle, D. (2015). Childhood socioeconomic deprivation, but not current mood, is associated with behavioural disinhibition in adults. Peer Journal, 3, e964. doi:10.7717/peerj.964

Pepper, G. V., \& Nettle, D. (2014). Socioeconomic disparities in health behaviour. In D. W. Lawson \& M. Gibson (Eds.), Applied Evolutionary Anthropology: Darwinian Approaches to Contemporary World Issues (pp. 225-243). New York: Springer.

Pettit, P. (1993). Negative liberty, liberal and republican. European Journal of Philosophy, 1(1), 15-38.

Pettit, P. (2007). A republican right to basic income? Basic Income Studies, 2(2), 1-8.

Psychologists for Social Change. (2017). Universal basic income: A psychological impact assessment. London: PAA.

Russell, M., \& Lough, M. (2010). Deprived areas: deprived of training? British Journal of Ceneral Practice, 60(580), 846-848.

Standing, C. (2011). The Precariat. London: Bloomsbury.

Standing, G. (2014). A precariat charter: from denizens to citizens. London: Bloomsbury.

Standing, C. (2015). The precariat and class struggle. RCSS Annual Review, 7, 3-16.

Stanfield, B. (2000). The art of focused conversation. Toronto: The Canadian Institute of Cultural Affairs.

Tang, K. L., Rashid, R., Godley, J., \& Chali, W. A. (2016). Association between subjective social status and cardiovascular disease and cardiovascular risk factors. British Medical Journal Open, 6(3), e010137.

Torry, M. (2013). Money for everyone. Bristol: Policy Press.

Toynbee, P., \& Walker, D. (2001). Did things get better? An audit of labour's successes and failures. London: Penguin.

Tudor Hart, J. (1971). The inverse care law. The Lancet, 297(7696), 405-412.

Verlinde, E., De Laender, N., \& De Maesschalck, S. (2012). The social gradient in doctor-patient communication. International Journal for Equity in Health [Online], 11, 12. doi:10.1186/1475-9276-11-12 [Accessed 4 August 2017].

Warwick Giles, L., Coleman, A., \& Checkland, K. (2016). Making Sense of Inequalities. Social Policy \& Administration. [Online First] doi:10.1111/spol.12227

Watt, G. (2002). The inverse care law today. The Lancet, 360(9328), 252-254.

Watt, G. (2011). Patient encounters in very deprived areas. British Journal of Ceneral Practice, 61(583), 146.

Widerquist, K. (2013). Independence, propertylessness, and basic income: A theory offreedom as the power to say no. New York: Palgrave Macmillan.

Willems, S., De Maesschalck, S., Deveugele, M., Derese, A., \& De Maeseneer, ]. (2005). Socio-economic status of the patient and doctorpatient communication. Patient Education and Counseling, 56(2), 139-146.

Wright, E. O. (2006). Two redistributive proposals. Focus, 24(2), 5-7. 